\title{
CAUSAL INFERENCE FROM DESCRIPTIONS OF EXPERIMENTAL AND NON-EXPERIMENTAL RESEARCH:
}

\section{Public Understanding of Correlation-Versus-Causation}

Katelyn Morrison and Luke Heidtke

Faculty Mentor: April Bleske-Rechek

\section{BACKGROUND:}

Humans are cognitive misers who fall prey to a variety of thinking biases, ${ }^{1,2}$ ncluding a bias toward seeing patterns between events and a tendency to search of correlation with causation ${ }^{3,4}$ The distinction between correlation and causation is emphasized in various college courses; however, previous research from our lab suggests that college students frequently incorrectly infer cause and effect relationships from correlational data. These incorrect inferences are made more often when the direction of the causal relationship seems intuitive, a bias that may be perpetuated by incorrect media and scholarly representation of correlational
findings. 5 Personal experiences and vivid testimonials also perpetuate this bias 6,7 findings. ${ }^{5}$ Personal experiences and vivid testimonials also perpetuate this bias. We designed three studies to investigate the inferences general community members draw from hypothetical descriptions of experimental and non-
experimental research on human behavior.

\section{VIGNETTE FOR STUDY 2:}

Studv 2: Self-Esteem and ACAdemic Performance

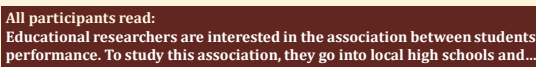
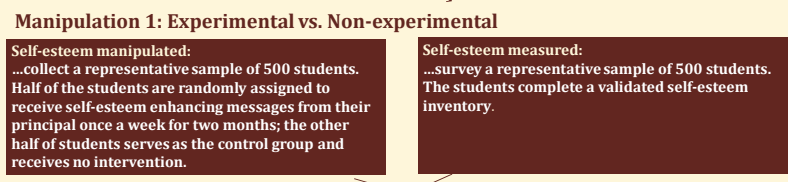

All participants read:
After two months, the

Manipulation 2: Positive vs. negative association
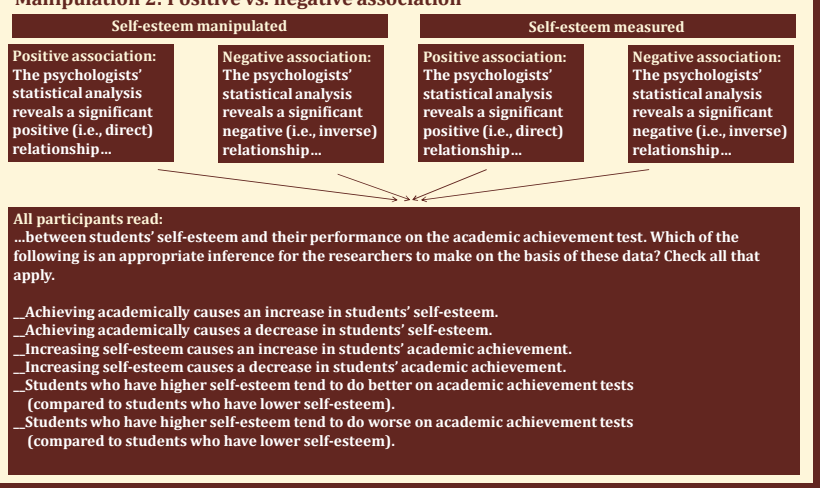

DISCUSSION

Participants' pattern of inferences in the three studies was consistent. First, across studies participants drew causal inferences from non-causal data just as ofte as they did from causal data. Second, they were more likely to infer directions of causality (positive versus negative effects) that coincided with common-sense
notions about the topic. Third, participants favored certain causal paths over others. For example, as shown in the Study 1 handouts, participants were more likely to infer that video game playing causes an increase in agoressiveness than to infer that agressiveness causes an increase in video game playing. Finally, to infer that video game playing causes an increase in aggressiveness than to infer that aggressiveness causes an increase in video game playing. Finally,
participants consistently chose the restatement of the probabilistic association they read about when the direction of the association coincided with their intuitive notions about how the two variables are related.

Despite that most participants favored statements that coincided with their preconceived notions, not all participants selected the inferences that were intuitiv and correct on the basis of the vignette. Perhaps these participants who were unwilling to select the restatement of the association represent the percent of people do better on academic achieveme tests" is synonym do better on academic achievement tests" is synonymous to saying that "any student who has high self-esteen will do better on acele
Future research may want to identify the mindware gaps that explain why some people view exceptions to a trend as refuting that trend.

Our findings raise concern about the tendency of media reports to conflate correlation and causation. If the average reader of research findings is prone to conflate correlation with causation, then those delivering the news must do their best not to mislead the already susceptible reader. Many media headlines advertise the "effects" or "consequences" of one variable on another when the research cited is non-experimental. These causal claims about correlational data often occur in
domains about which readers have strong emotions or opinions, which can make them even more susceptible to these biases. Scientists and educators should focus on ways to intervene and enhance people's ability to reason about causal and non-causal trends.

\section{RESULTS:}

Study 2: Self-esteem and Academic Achievement

Achieving academically causes
an increase in students' self-esteem.

Achieving academically causes
a decrease in students' self-esteem.

Increasing self-esteem causes an increase
in students' academic achievenent.

Increasing self-esteem causes a decrease
in students' academic achievement.

Students who have higher self-esteem tend
to do better on academic achievement tests.

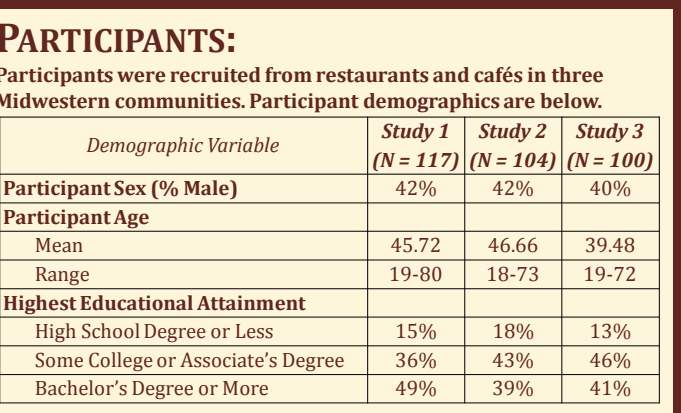

\section{PROCEDURE:}

Each study was a $2 \times 2$ between-subjects design. Participants read one of four each study were (1) whether the research vignette described an experimest design or a non-experimental design and (2) whether the research vignette described a positive relationship between the variables or interest or a negative relationship between the variables of interest. After reading the vignette, participants selected which of six inferences they could draw from the results of the research. The layout of information participants in Study 2 received is presented below. The layout for Studies 1 \& 3 is identical; see handouts. Study 1 participants read about video games and aggressiveness; Study 2 participants 位

The first thing we assessed was the rate at which participants who were exposed to an experimental vignette (self-esteem manipulated) drew correct causal
inferences. For participants who received a positive association, $82 \%$ correctly inferred correctly that increasing self-esteem causes an increase in achievement. For participants who were told the association was negative, only $38 \%$ correctly inferred that increasing self-esteem causes a decrease in between self-esteem and achievement, $\mathbf{7 0} \%$ of participants incorrectly inferred that increasing self-esteem causes an increase in achievement, just as $82 \%$ of experimental vignette describing a negative association, $24 \%$ incorrectly inferred that increasing self-esteem causes a decrease in achievement, similar to

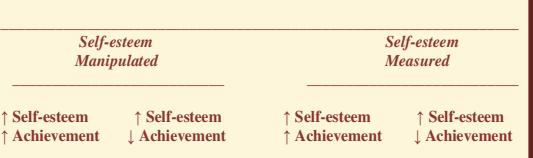

\section{teem}

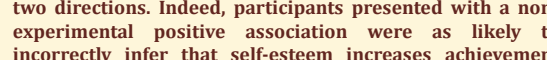
incorrectly infer that self-esteem increases achievement
$(70 \%)$ as they were to incorrectly infer that achievement increases self-esteem $(74 \%)$. Participants receiving a nonexperimental negative association were less likely to make incorrect inferences about negative causal effects of selfesteem (32\%). Instead they flipped the direction of the esteem $(32 \%)$. Instead, they flipped the direction of the
effect and incorrectly concluded that self-esteem causes an increase in achievement (56\%) and that achievement causes an increase in self-esteem (56\%). Similarly, for participants receiving the negative association, their notion about how self-esteem and achievement go together biased their
interpretation of the association. When provided with inferences that merely restate the association, only $37 \%$ selected the correct restatements (compared to $82 \%$ of $36 \%$ participants who had received the positive association). addition, participants who received the vignettes depicting the negative

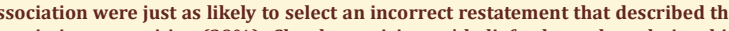
between the variables holds weight, even in the face of contrary findings.

\section{REFERENCES:}

Kaplan, M. \& Kaplan, E. (2009). Bozo Sapiens: Why to err is human. New York, NY: Bloomsbury Press.
'Stanovich, K. E. (2009). What intelligence tests miss: The psychology of rational thought New Haven, CT. Yale University Press.

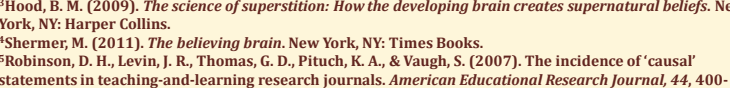

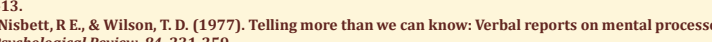
sychological Review, 84, 231-259.
Stanovich, K. E. (2010). How to think straight about psychology (9th ed.). Boston, MA: Allyn \& Bacon. ACKNOWLEDGEMENTS: We thank the Office of Research and Sponsored Programs for their support of this project, especially via
2013 summer Research Experiences for Undergraduates grant. We also thank Dr. Mary Beth Leibham and 